\title{
Overcoming Students' Misconceptions on Forces in Equilibrium: An Action Research Study
}

\author{
Lilia Halim, Tan Kia Yong, Tamby Subahan Mohd Meerah \\ Faculty of Education, Universiti Kebangsaan Malaysia, Bangi, Malaysia \\ Email: lilia@ukm.my
}

Received 18 February 2014; revised 13 March 2014; accepted 2 April 2014

Copyright (C) 2014 by authors and Scientific Research Publishing Inc.

This work is licensed under the Creative Commons Attribution International License (CC BY).

http://creativecommons.org/licenses/by/4.0/

(c) (i) Open Access

\begin{abstract}
This collaborative action research involving a supervisor and a student teacher aims to assist 23 Form Four (16 years old) students to overcome their misconceptions on the topic of forces in equilibrium state. This study adopts the action research cycle: Identify-Plan-Act-Reflect. The pre-test results showed that students had problems in recognizing the forces. Consequently, a teaching intervention was planned and carried out to improve students' ability to identify and recognize the forces that exist for an object in the equilibrium state. The teaching intervention emphasizes on the basic characteristics of the force arrow namely the direction, magnitude, labeling and starting point of force. The post test results showed that students' ability to draw the force arrows correctly had improved, with the exception of identifying the starting point of force. The action research study managed to guide the student teacher to identify and help to overcome misconceptions of her students.
\end{abstract}

\section{Keywords}

Collaborative Action Research, Students' Misconception, Teaching Instruction, Physics, Forces

\section{Introduction}

Physics is introduced to upper secondary students (16 years old). However, it is a general fact that most students have a negative perspective about Physics. This is because they do not obtain high marks in examination even though they have tried their best. This phenomenon is caused by misconception and lack of understanding about basic Physics concepts. Many researchers have shown that students tend to develop the understanding about natural phenomenon before formal teaching was conducted. Ideas developed by students which differ from 
scientific explanation are known as misconceptions (Chambers \& Andre, 1997; Hammer, 1996; Lawson, 1995) and these misconceptions are too strong to overcome and can inhibit the process of teaching and learning (Gunstone, 1995). Initial ideas held by students are very difficult to change by teacher despite being presented with scientific concepts (Tsai, 1999; Sencar \& Eryilmaz, 2004). Teachers should identify students' misconception before conducting formal teaching so that their misconception can be changed to scientific concept after the formal teaching and learning process (Wong \& Seth, 2008).

Halim et al. (2009) state that to build an effective model of teaching and learning for teaching physics it should begin by exploring or identifying difficulties and misunderstanding faced by students using diagnostic tests. Several studies have found that misconception still exist even when the students have attended more Physics class. The same misconception occurs and exists at primary and up to university level. This shows that normal or regular teaching and learning process is unable to overcome misconception if the focus of the teaching is not targeted on the misconception. One of the difficulties to overcome the misconception is that the teachers themselves are not being trained to overcome the misconception. Osman et al. (2006) added, even though the role of quality Science teacher has been realized, but like many countries (e.g. Pakistan, Australia, New Zealand, United States of America and Britain), Malaysia is facing the problem of inadequate trained Science teachers especially in the teaching of Physics, Chemistry and Mathematics. As a result, teachers who are not trained in teaching Science subjects are often required to teach Science. If nothing is done to help this group of teachers, they probably are unable to implement Science curriculum effectively. The study of student misconceptions in Physics has become both an important concern for Physics education research and a valuable tool for the practicing physics teacher (Styer, 1995; Abell \& Lederman, 2007). Although some misconceptions are difficult to overcome, teachers must be aware about the existence of the misconception and keep addressing to overcome students' misconceptions so that students will have conceptual understanding.

The study of this phenomenon needs to be solved by taking specific action namely by having collaborative relationship between university professors and student teachers to plan a specific action to be implemented. This has encouraged the researchers to explore physics misconception in the topic of mechanics and forces in equilibrium.

\section{Initial Reflection}

During the teaching and learning process on topic forces in equilibrium, the student teacher found that most of the students have misconceptions on this topic. Some students do not understand why an object that is moving with constant velocity is said to be in equilibrium state. The school students argue that, as long as the object is moving (in constant velocity or not), the object should be in a state of imbalance. Due to the imbalance force, the object will move. However, if the object is in equilibrium state or balance state, the object should be static and not moving. This misconception arises both from the students and the student teacher herself; who had neglected the word "constant velocity" and only takes into account of the initial motion of the object. By taking into account the initial motion of the object, where forces are acting on the car, of course the object is not in equilibrium state as the forces are in the imbalanced state.

\section{Purposes of Study}

The aim of this research was to overcome students' misconception in the concept of equilibrium forces which is implemented through the following research objectives, namely:

(1) to enhance students' ability in identifying forces arrow (arrow representing force), and

(2) to enhance students' ability in drawing the forces arrow (arrow representing force) for objects the state of equilibrium.

More specifically the study aims to answer the following research questions:

(1) Can students identify the forces exerted on an object based on the forces arrow (arrow representing force)?

(2) What is the suitable intervention teaching strategy to help students to identify and drawing forces arrow (arrow representing force)?

(3) To what extent the intervention strategy facilitates students' understanding of basic concepts of forces and the ability to draw the forces arrow (arrow representing force) in equilibrium state? 


\section{Methodology}

This collaborative action research between a university professor (practicum supervisor) and a student teacher was conducted on Form Four students in Selangor. The respondent for this research were 23 students taking Physics. Two test instruments were used: (a) pre-test and (b) post-test which was developed by the Head Teacher of Science. Four-phase action research cycle was used for this research namely: (a) Initial reflection phase-based on the student teacher's teaching experience to determine the focus of teaching and learning on misconception, (b) Intervention action plan phase- based on the reflection between the practicum supervisor and student teacher based on pre-test analysis and literature review, (c) Implementation and data collection phaseconducted by the student teacher then followed by a post-test on school students, and (d) Analysis of data and reflection phase-includes discussion and comparison of the pre and post-test findings and reflection on action to be taken. The analytical scheme of answers for both pre and post-tests was described in detail.

\section{Pre Test}

The test consists of pictures of 12 objects ranging from an object in static, moving with constant velocity and object in accelerating motion. Students are required to draw arrows representing the forces exerted on the object. Force arrow (arrow representing force) cover three aspects namely, the direction, the magnitude and type of force. Example of pre-test question is in Appendix 1. Student responses were analyzed based on four aspects namely, direction of the arrow, size of the arrow, labeling of the arrow and starting point of the force. Then, each aspect is divided into three levels i.e. complete, half complete and wrong answers. Example of this analytical scheme is shown in Appendix 2. Results of the analysis (Table 1) show that a large number of students are unable to identify the forces exerted on an object as they are unable to draw forces arrow

Table 1. Number of students who answer completely, partial complete and wrongly for each situation in pre-test and posttest type styles.

\begin{tabular}{|c|c|c|c|c|c|c|c|}
\hline \multirow{3}{*}{ Situation } & \multirow{3}{*}{ Component } & \multicolumn{6}{|c|}{ Number of Student } \\
\hline & & \multicolumn{2}{|c|}{ Complete } & \multicolumn{2}{|c|}{ Incomplete } & \multicolumn{2}{|c|}{ Wrong } \\
\hline & & Pre & Post & Pre & Post & Pre & Post \\
\hline \multirow{4}{*}{$\begin{array}{l}\text { A Book/Brick Resting on } \\
\text { the Table }\end{array}$} & Direction of arrows & 12 & 22 & 4 & 0 & 7 & 1 \\
\hline & Size of arrows & 9 & 19 & 4 & 0 & 10 & 4 \\
\hline & Labeling & 4 & 21 & 3 & 1 & 16 & 1 \\
\hline & Starting points of arrows & 0 & 8 & 0 & 14 & 23 & 1 \\
\hline \multirow{4}{*}{ A Man Pushing Wall } & Direction of arrows & 0 & 4 & 3 & 19 & 20 & 0 \\
\hline & Size of arrows & 0 & 0 & 4 & 15 & 19 & 8 \\
\hline & Labeling & 0 & 0 & 2 & 23 & 21 & 0 \\
\hline & Starting points of arrows & 0 & 3 & 1 & 20 & 22 & 0 \\
\hline \multirow{4}{*}{$\begin{array}{l}\text { Skydiver falling at } \\
\text { Terminal/Constant Velocity }\end{array}$} & Direction of arrows & 5 & 22 & 2 & 0 & 16 & 1 \\
\hline & Size of arrows & 2 & 21 & 2 & 0 & 19 & 2 \\
\hline & Labeling & 0 & 19 & 2 & 3 & 21 & 1 \\
\hline & Starting points of arrows & 0 & 13 & 1 & 8 & 22 & 2 \\
\hline \multirow{4}{*}{$\begin{array}{l}\text { An Airplane is moving with } \\
\text { Constant Velocity }\end{array}$} & Direction of arrows & 5 & 22 & 13 & 1 & 10 & 0 \\
\hline & Size of arrows & 2 & 2 & 12 & 17 & 11 & 4 \\
\hline & Labeling & 0 & 10 & 3 & 13 & 20 & 0 \\
\hline & Starting points of arrows & 0 & 17 & 0 & 6 & 23 & 0 \\
\hline \multirow{4}{*}{$\begin{array}{l}\text { A picture Hanging on } \\
\text { the Wal }\end{array}$} & Direction of arrows & 0 & 20 & 11 & 3 & 12 & 0 \\
\hline & Size of arrows & 0 & 15 & 11 & 7 & 12 & 1 \\
\hline & Labeling & 0 & 10 & 3 & 13 & 20 & 0 \\
\hline & Starting points of arrows & 0 & 17 & 0 & 6 & 23 & 0 \\
\hline
\end{tabular}


(arrow representing force) correctly either in terms of direction, magnitude, labeling types of forces and its starting point.

\section{Action and Implementation Plan}

Based on the initial reflection phase, the practicum supervisor and the student teacher designed a teaching strategy aimed at teaching students on how to identify and draw forces arrow (arrow representing force) in equilibrium state either in the vertical or horizontal situation. If these fundamental conditions are not understood, understanding forces in other conditions such as an object moving with acceleration and “inclined plane” will be hampered.

In general, the teaching process began by introducing the concept of force, categories of force such as "contact force" and "field force" and types of forces. For both "contact force” and "field force”, their starting points represented by forces arrow (arrow representing force) are different. "Contact force” is the force produced when two objects interact physically, so the starting point of the arrow starts at the surface of the object. While "field force" is the force produced when two objects interact but not physically in contact, so the starting point of the arrow is at the center of the object. When describing type of forces, the teaching methods used to identify and label of forces was shown using demonstration and animation. Learning Physics concepts through animation courseware has been shown to lead to a positive relationship on student achievement and changes in concept understanding (Wenglinsky, 1998; James \& Lamb, 2000; Weaver, 2000; Jimoyiannis \& Komis, 2001). At the end of the lesson, example of diagrams containing wrong identification and labeling method is given to the students with intention to test their understanding in drawing forces arrow (arrow representing force).

Some analogy in form of demonstration were used for the following situations in the teaching strategy: (a) A book resting on the table, (b) A man pushing wall, (c) Skydiver falling at constant/ terminal velocity, (d) An airplane moving at constant velocity and (e) A picture hanging on the wall. The demonstrations are conducted by the students' themselves. Modifications of the demonstration for the analogy have proven their effectiveness (Brown, 1987; Thornton \& Sokoloff, 1998; Demirci, 2005; Muller et al., 2007; David, 2008). To explain the situation and forces involved for a book resting on the table, a student was asked to demonstrate in front of the class. The student extended both arms representing as a desk and a thick book is placed on her palm. At the beginning, when the thick book is placed onto the hands of the students, her hand moved slightly downwards. Meanwhile, other students are required to observe the movement. Then, the students will exert a force to lift the thick book which represents the book on the table was in equilibrium state.

Next, to explain a situation where a man is pushing the wall, two students were requested to conduct the demonstration. Student A will act as the wall whereas student B will act as the person pushing the wall. The palms of two students are in contact (Touching each other). Initially, student B will exert a force and push student A. As a result, student A will move backwards as she did not impose any force. Meanwhile, other students are required to observe the situation. Through this demonstration, it is proven that, if the wall does not impose any force on those pushing on it, the wall will move backwards. However, this will not happen when we push on the wall. So now, student A will exert a force to withstand the repulsive force by student B. Thus, both students will be in a static and in balanced state. This shows that the wall also exerts a normal force to us when we push the wall.

For the third situation where a skydiver falls with a constant/terminal velocity, the student teacher showed an animated skydiver falling down using MS Power Point. Animated falling skydiver will initially fall with gravitational acceleration, and then he will fall with constant velocity. Gravitational force and frictional force are shown beside the animation using forces arrow (arrow representing force) with values and formula for acceleration to achieve a balance force state so that the skydiver will move at a constant velocity. By drawing forces arrow (arrow representing force) to show all forces acting on the skydiver, it is hoped that the students will be able to see clearly that skydiver moving at constant velocity is in a state of equilibrium (balance force).

For the fourth situation, an airplane moving with constant velocity, the student teacher use spring balance and rings for demonstration. The ring was tied to a thread and the ring was being pulled by four spring balance, the ring is static and in the equilibrium state. If two opposite spring balance pulled the ring with a force more than others, the ring will move with constant velocity. Spring balances were used to indicate that forces that are being applied. Thus, students can see that an object moving with constant velocity horizontally like an airplane; actually has four imposing force acting on it. To be added, two out of four forces have opposing forces with equal 
magnitude. This shows that, an airplane which is moving in a constant velocity has a balance force or in equilibrium state. To explain the fifth situation where a picture is hanging on the wall, the student teacher showed an animation regarding a picture being hung on the wall which is in equilibrium state using Physics courseware. This animation explains how forces are being applied to the rope and why the picture on the wall is in balance state.

With the guided animation, students were asked what types of forces are acting on the picture? If the forces applied on top and bottom of the picture are not the same, what will happen to the picture? If one of the forces exerted on the rope is greater than others, what will happen to the picture? With this, students realize that two forces acting on the picture and forces on both side of the string must have equal magnitude to keep the picture in balance state. In addition student were informed to ensure that forces arrow (arrow representing force) must be drawn in full and not using the rope as part of the forces arrow (arrow representing force). This is because, students often make mistake by using the rope as part of the forces arrow (arrow representing force). After the intervention, students were given a new set of questions in forms of forces arrow (arrow representing force) in equilibrium state to test students' understanding on drawing forces arrow (arrow representing force) (Appendix 3). Using the same analytical scheme for the pre-test, the results revealed that students had a better understanding on how to draw the forces arrow (arrow representing force) than before in all aspects. Even though not all questions were answered correctly but overall they had improved a lot.

\section{Findings}

Figure 1 shows the comparison of the test scores for pre and post-tests scored by 23 students for each question. Meanwhile, Table 1 reports a comparison between the numbers of students who are able to answer completely, partially complete and wrong for each question in pre and post-test. As a comparison, the total marks obtained by student in pre-test and post-test (Figure 1) for a situation where a book rest on table shows less improvement compared to other situations. This is because, the total marks obtained by the students in the pre-test is higher compared to other situation as this situation is quite common and often to be seen in Physics reference book.

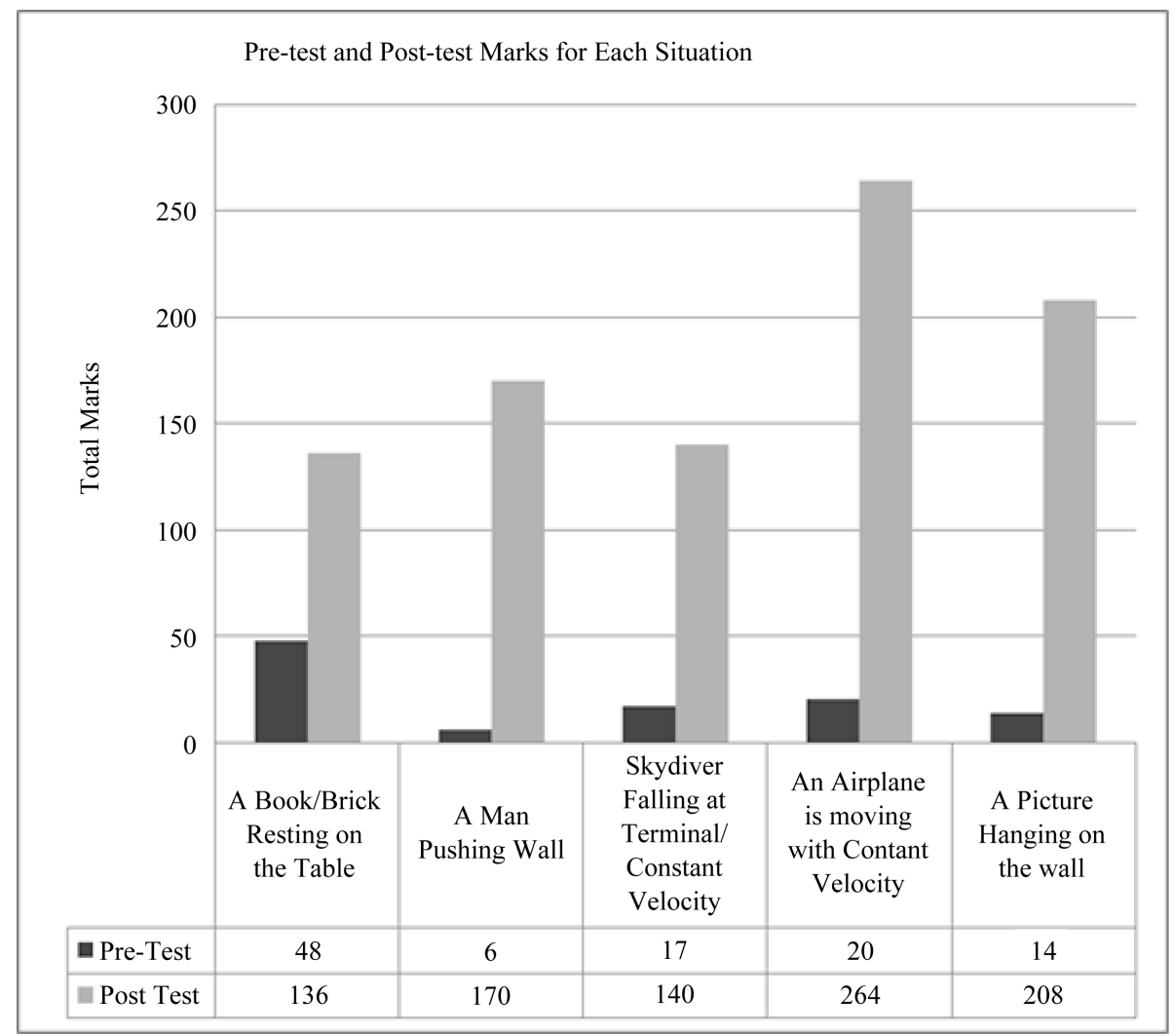

Figure 1. Comparison of pre and post tests scores. 
However, students still have problems in labeling and identifying the starting point of the forces arrow (arrow representing force).

This is because they tend to memorize the diagram without understanding it. As a result, they have problems in identifying types of forces that are involved in the situation. So, the score on pre-test is not likely to show that students really understand the concept of balance force for a book on the table. However, an increase in post test score marks for a situation where a book is placed on the table, especially in terms of the direction of the forces arrow (arrow representing force) showed that the demonstration technique used in intervention process is effective and able to enhance students' understanding on the concept of forces for this situation. Therefore, all students should be given an opportunity to do demonstration in their respective groups so that they can experience, identify and draw type of forces involve in equilibrium state.

Next, the highest increment in total scores is for the situation where an airplane moves with constant velocity. Nevertheless, the demonstration could be improved by using a larger spring balance and ring so that students can see the demonstration clearly and this indirectly increase their understanding on the basic concepts of forces for this situation. Table 1 also shows that most students have problem regarding the size of the forces arrow (arrow representing force) when they draw them. This reveals that students are unable to identify magnitude of the forces being exerted on an object in equilibrium state. This is probably because that the magnitude of the forces is not visible to our naked eye and requires "formal thinking" to understand the concept of magnitude for forces arrow (arrow representing force). Thus, the concept of magnitude for forces arrow (arrow representing force) should be emphasized more in the intervention process. In addition, to assist students in determining the magnitude of forces being exerted on an object, a force measuring instrument can be used such as spring balance so that the students are able to see clearly the magnitude of forces involved. Using an analogy to represent certain situation also helps to improve students' understanding. For example a situation where an airplane moves with constant velocity is demonstrated using spring balance and ring. With this analogy, students are able to determine the magnitude of forces involved and have better understanding in the concept of magnitude. As a result, students will be able to draw the size of the forces arrow (arrow representing force) correctly.

Apart from the size of the forces arrow (arrow representing force), most students can only draw partially complete forces arrow (arrow representing force) for a situation where a man is pushing the wall. This indicates that most students still do not understand the concept of forces arrow (arrow representing force) and they are unable to identify all the forces acting in that situation. Students might have difficulty identifying forces in a static motion compared to a moving object. Thus the demonstration where two students were pushing each other needs to be revised and modified. The proposed modification is to put two weight scales between the two students; one student act as a person pushing the wall and another student act as a wall. Assuming the readings shown on the weight scale represents the magnitude of the forces, and then the amount of forces exerted by the two students can be measured and seen by other students.

Besides that, the force exerted by a person who is pushing the wall or floor can be associated with a situation where a book is placed on the table by assuming the person as a book and the wall or floor as a table. Demonstration activity was being performed repeatedly by the student and this improves their understanding for a situation where a man is pushing the wall. To conclude based on Table 1 it is found that students' achievements and understanding has improved. The number of students who can draw forces arrow (arrow representing force) completely in post-test also increases tremendously compared to pre-test. This indicates that the intervention process is effective.

\section{Discussion and Conclusion}

Reflecting on the intervention process, we proposed some adjustments to improve the practice, particularly in the action plan. At the same time, some fundamental steps need to be addressed before the intervention process is implemented. Even though an intervention was conducted, it was found that there are students who are unable to describe and identify forces that exist on an object in equilibrium state. An explanation for this is that, as shown in earlier studies, misconceptions are difficult to overcome. Another reason is also that students' thinking might not have reached the level of "formal thinking" in understanding the scientific concept which is often abstract.

This shows that students' thinking level is very important in understanding the abstract concepts of physics such as the concept of force. According to Piaget's theory of cognitive development, students' thinking level 
between the ages of 11 to 15 years should have reached the level of "formal thinking”, but the development is not the same for all. Therefore, the focus of intervention activities namely in improving students' thinking level should be conducted in the next research. Each student has a different thinking level, therefore researcher and teacher must investigate their thinking level whether the students' thinking level has reached "formal thinking" or still in "concrete thinking" before planning any intervention strategy. By knowing the students' thinking level, teachers are able to design the intervention strategies to assist the student in enhancing their thinking level from "concrete thinking" to "formal thinking" which then allows the students to understand the abstract concept of forces. A module can be used to improve students' thinking level which is "Cognitive Acceleration through Science Education (CASE)". CASE is a module used to improve students' "formal thinking” in learning science.

Thus, this intervention should be carried out first, before the intervention related to the teaching on the concept of forces is implemented. This study also demonstrates that more active learning strategies which focus on the students and discussion activity help students to gain meaningful understanding thus more of such strategies should to be considered for the next research. McKinney (2004) argues that active learning is “... techniques where students do more than simply listen to a lecture. Students are doing something including discovering, processing and applying information”. Thus, by using active learning, teachers can challenge students' thinking and improve their understanding in the concept of forces.

This collaborative action research has been successful in helping students to improve their skills in identifying forces in equilibrium by drawing correct forces arrow and overcoming some misconceptions on the concept of forces. The teaching and learning process for this research helps students in understanding the fundamental nature of forces, methods in drawing forces arrow and ways to overcome misconception for static and constant velocity state. Teaching based on action research is seen effective to overcome misconceptions.

\section{References}

Abell, S. K. \& Lederman, N. G. (2007). Handbook of Research on Science Education. Mahwah, NJ: Lawrence Erlbaum Associates

Brown, D. E. (1987). Using Analogies and Example to Help Students Overcome Misconception in Physics: A Comparison of Two Teaching Strategies. Unpublished Doctoral Thesis of Education, Amherst, MA: University of Massachussetts.

Chambers, S. K., \& Andre, T. (1997). Gender, Prior Knowledge, Interest, and Experience in Electricity and Conceptual Change Text Manipulations in Learning about Direct Current. Journal of Research in Science Teaching, 34, 107-123. http://dx.doi.org/10.1002/(SICI)1098-2736(199702)34:2<107::AID-TEA2>3.0.CO;2-X

David, R. W. (2008). Science Discrepant Events and Critical Thinking: Using Surprising Phenomena to Focus Students’ Attention in Science.

http://teachertipstraining.suite101.com/article.cfm/science_discrepant_events_and_critical_thinking\#ixzzWwBWODcg

Demirci, N. (2005). A Study about Students’ Misconceptions in Force and Motion Concepts by Incorporating a Web-Assisted Physics Program. The Turkish Online Journal of Educational Technology, 4, 40-49.

Gunstone, R. F. (1995). The Importance of Specific Science Content in the Enhancement of Metacognition. In P. J. Fensham, R. F. Gunstone, \& R. T. White (Eds.), The Content of Science: A Constructivism Approach to Its Teaching and Learning (pp. 131-146). London: The Falmer Press.

Halim, A., Meerah, T., \& Halim, L. (2009). Development and Application of Diagnostic Test to Identify Students’ Misconception on Quantum Physics. Sains Malaysiana, 38, 543-551.

Hammer, D. (1996). More than Misconceptions: Multiple Perspectives on Student Knowledge and Reasoning, and an Appropriate Role for Education Research. American Journal of Physics, 64, 1316-1325. http://dx.doi.org/10.1119/1.18376

James, R., \& Lamb, C. (2000). Integrating Science, Mathematics, and Technology in Middle School Technology-Rich Environments. A Study of Implementation and Change. School Science and Mathematics, 100, 27-35. http://dx.doi.org/10.1111/j.1949-8594.2000.tb17317.x

Jimoyiannis, A., \& Komis, V. (2001). Computer Simulations in Physics Teaching and Learning: A Case Study on Students’ Understanding of Trajectory Motion. Journal of Computers \& Education, 36, 183-204.

http://dx.doi.org/10.1016/S0360-1315(00)00059-2

Lawson, A. E. (1995). Science Teaching and the Development of Thinking. Belmont, CA: Watsworth Publishing Company.

McKinney, K. (2004). How Sociology Majors Learn Sociology: Successful Learners Tell Their Story. Journal of Scholarship of Teaching and Learning, 4, 15-24.

Muller, D. A., Bewes, J., Sharma, M. D., \& Reimann, P. (2007). Saying the Wrong Thing: Improving Learning with Multimedia by Including Misconceptions. Journal of Computer Assisted Learning, 24, 144-155. 
http://dx.doi.org/10.1111/j.1365-2729.2007.00248.x

Osman, K., Halim, L., \& Meerah, T. S. M. (2006). What Malaysian Science Teachers Need to Improve Their Science Instructions: A Comparison a Cross Gender, School Location and Area of Specialization. Eurasia Journal of Mathematics, Science and Technology Education, 2, 58-81.

Sencar, S., \& Eryilmaz, A. (2004). Factors Mediating the Effect of Gender on Ninth-Grade Turkish Students' Misconceptions Concerning Electric Circuits. Journal of Research in Science Teaching, 41, 603-616.

http://dx.doi.org/10.1002/tea.20016

Styer, F. D. (1995). Common Misconceptions Regarding Quantum Mechanics. American Journal of Physics, 64, 31-34. http://dx.doi.org/10.1119/1.18288

Thornton, R. K., \& Sokoloff, D. R. (1998). Assessing Student Learning of Newton's Laws: The Force and Motion Conceptual Evaluation of Active Learning Laboratory and Lecture Curricula. American Journal of Physics, 66, 338-352. http://dx.doi.org/10.1119/1.18863

Tsai, C. C. (1999). Overcoming Junior High School Students’ Misconceptions about Microscopic Views of Phase Change: A Study of an Analogy Activity. Journal of Science Education and Technology, 8, 83-91. http://dx.doi.org/10.1023/A:1009485722628

Weaver, G. C. (2000). An Examination of the National Educational Longitudinal Study (NELS: 1. Database to Probe the Correlation between Computer Use in School and Improvement in Test Scores. Journal of Science Education and Technology, 9, 121-133. http://dx.doi.org/10.1023/A:1009457603800

Wenglinsky, H. (1998). Does It Compute? The Relationship between Educational Technology and Student Achievement in Mathematics. Princeton, NJ: ETS Policy Information Center.

Wong, T. K., \& Sulaiman, S. (2008). The Level of Alternative Framework among Form Five Science Stream Students on the Topic of Buoyancy. National Conference of Science and Mathematics Education, Johor, Malaysia.

http://eprints.utm.my/7669/ 


\section{Appendix 1}

Example of Pre Test Questions

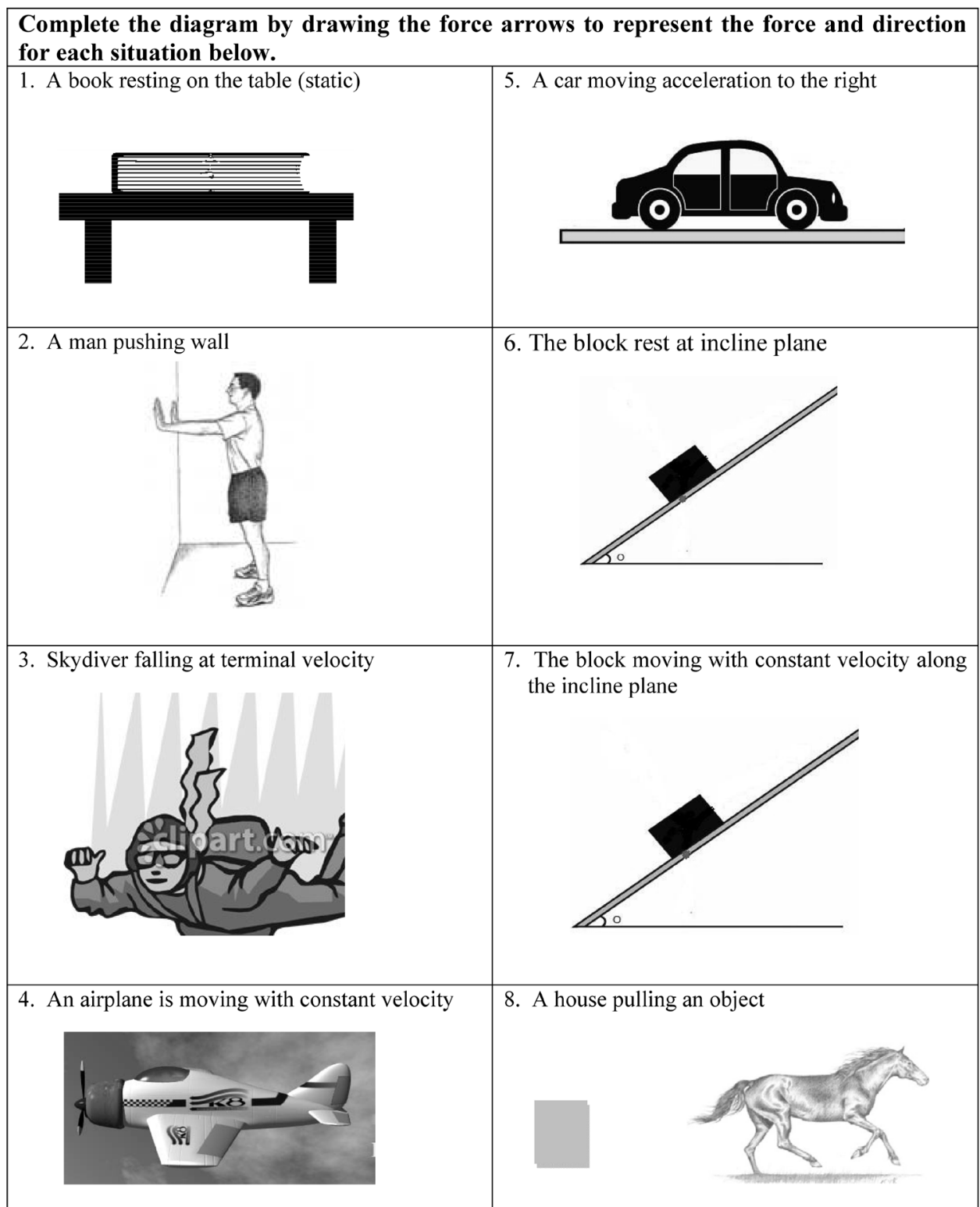

\section{Appendix 2}

Example of Analytical Answer Scheme

\section{A Man Pushing Wall}

Horizontal (Equilibrium State)

Force arrow must draw on the person (hand/feet)

(Item: Direction of Force Arrows)

(Consider the direction of force arrows only) 


\section{Complete Answer (4 marks)}

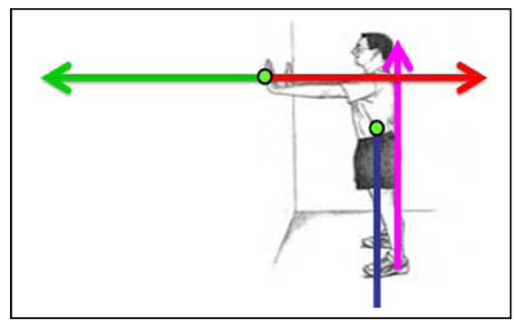

Examples of Incomplete Answer 25\% (3 marks)

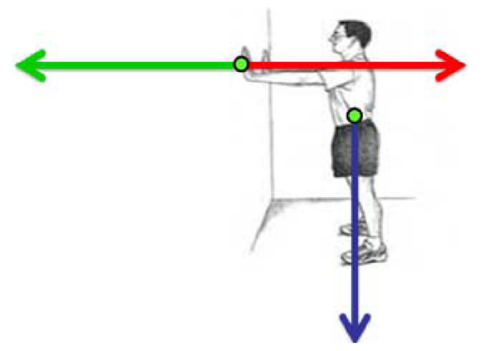

or

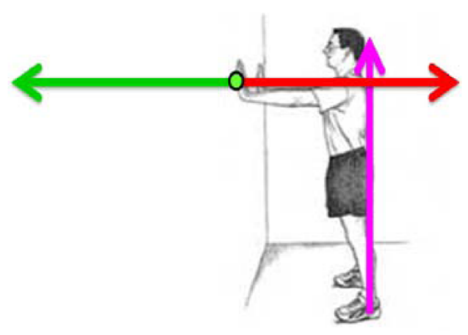

Examples of Incomplete Answer $50 \%$ (2 marks)

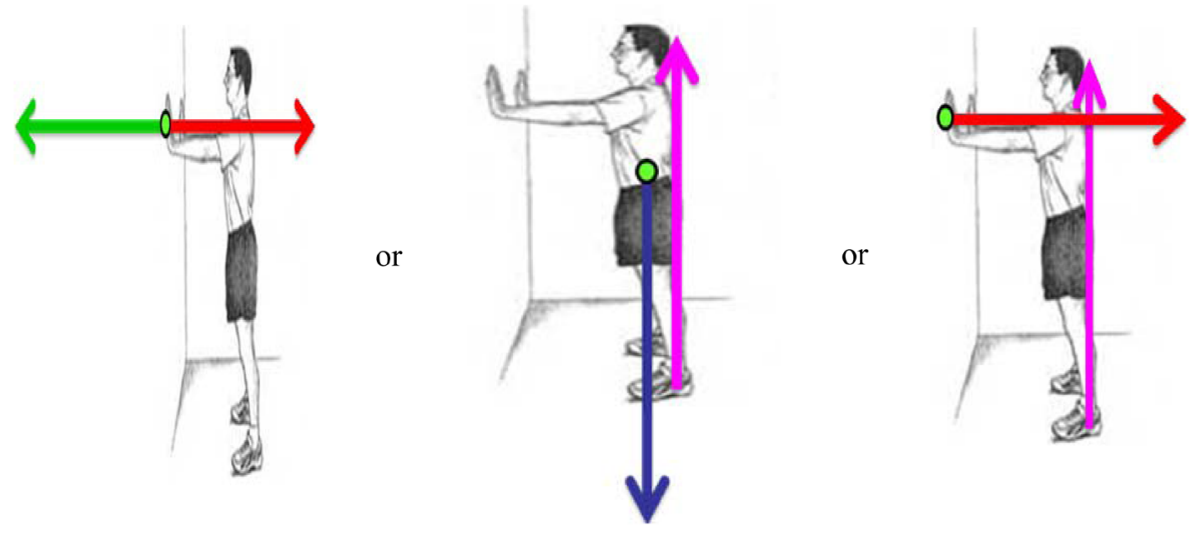

Examples of Incomplete 75\% (1 mark)

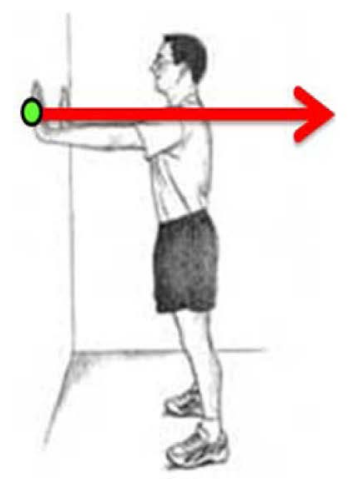

or

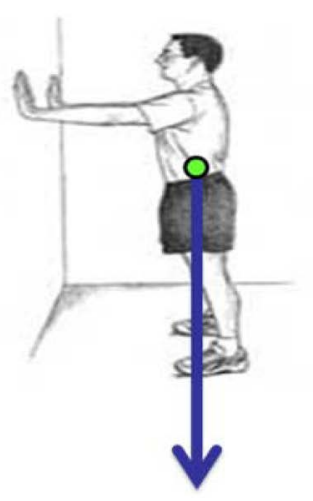




\section{Examples of wrong answer(0 mark)}
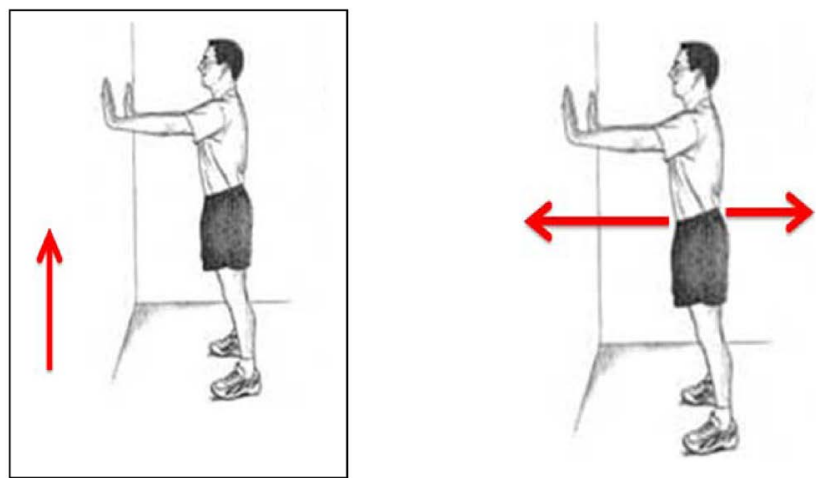

\section{Appendix 3}

Example of Post Test Questions

Complete the diagram by drawing the force arrows to represent the force and direction for each situation below.

1. An airplane is moving with constant
velocity


Scientific Research Publishing (SCIRP) is one of the largest Open Access journal publishers. It is currently publishing more than 200 open access, online, peer-reviewed journals covering a wide range of academic disciplines. SCIRP serves the worldwide academic communities and contributes to the progress and application of science with its publication.

Other selected journals from SCIRP are listed as below. Submit your manuscript to us via either submit@scirp.org or Online Submission Portal.
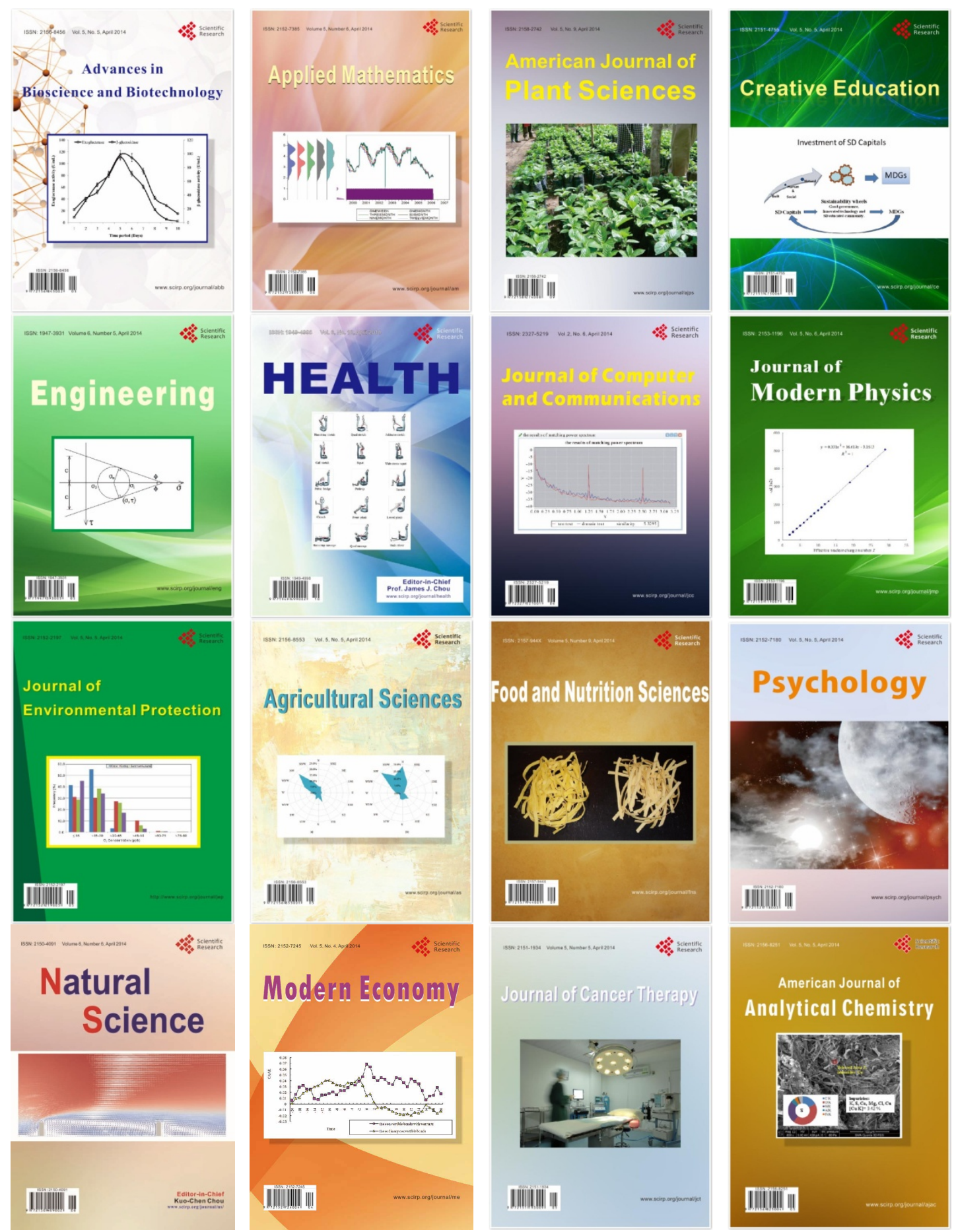